\title{
Gender differences in suicidal ideation and somatic symptoms in adolescents with depressive features
}

\author{
Anushree Gupta ${ }^{1}$ \\ ${ }^{1}$ Post graduate student, Department of Psychology, Maniben Nanavati Women’s College, Mumbai. \\ E-mail-anu0131@gmail.com
}

\begin{abstract}
Background: Patients with depression may show a variety of symptoms that range from cognitive symptoms to affective features, somatic symptoms and suicidal ideation. The aim of the present study was to assess suicidal ideation and somatic symptoms across gender amongst adolescents that reported depressive features when compared to those who did not do so.

Methodology: Sixty adolescent males and sixty adolescent female students were screened for depressive symptoms. The adolescents were then screened on basis of high depressive symptoms and low or no depressive symptoms. They were given the Beck Depression Inventory, Patient Health Questionnaire and Suicide Behavior Questionnaire - revised for assessment. MANOVA was used in the statistical assessment.

Results: It was found that females scored significantly higher on somatic symptoms as compared to males. Those who scored high on depressive symptoms scored significantly higher on suicidal ideation and somatic symptoms. As a group women with high depressive symptoms scored highest on both somatic symptoms and suicidal ideation.

Conclusion: The present study revealed that adolescents with depressive symptoms show both significantly higher rates of suicidal ideations and somatic symptoms. Female students were more likely to experience somatic symptoms.
\end{abstract}

ABSTRACT

Keywords: gender, gender differences, suicidal ideation, somatic symptoms, adolescents, depressive features.

(Paper received $-25^{\text {th }}$ May 2016, Peer review completed $-20^{\text {th }}$ July 2016, Accepted $-8^{\text {th }}$ August 2016)

\section{INTRODUCTION}

Depression is a state of low mood and aversion to activity that can affect a person's thoughts, behaviour, feelings and sense of well-being. Depression is an affective, or mood disorder. It is an illness that immerses its sufferers in a world of self-blame, confusion, and hopelessness. It is an illness of the mind and the body. Some could argue depression is a way of coping with life's pressures [1]. Depressive symptoms include frequent sadness, tearfulness, crying, hopelessness, decreased interest in activities, persistent boredom; low energy, social isolation, poor communication, low self-esteem and guilt, extreme sensitivity to rejection or failure, increased irritability, anger, or hostility, difficulty with relationships, a major change in eating and/or sleeping patterns with poor concentration [2].

An offshoot of the behavioural model in depression is Beck's cognitive-behavioural view of depression. Depressed patients suffer from a kind of basic thinking that distorts reality. They distort reality by harbouring negative feelings about anything and everything. They tend to take things too personally and believe the future is bleak and dim. These inferior feelings, lead to more negative experiences for the depressive. In turn, the patient develops thoughts of worthlessness and inferiority [3-4]. 
In particular, social environment plays a large role in many of the theories of depression. Continuous flawed or negative perceptions and interpretations of social surroundings can be detrimental to emotional state. In addition to social aspects, psychological and biological factors expand upon our knowledge of depression [5].

Women are twice more likely than men to suffer from depression. Women have a 20 percent to 26 percent lifetime risk of developing depression, compared to an 8 percent to 12 percent lifetime risk for men. $6 \%$ of women who suffer from depression require hospitalization, while half as many men $(3 \%)$ require hospitalization [6]. There are several explanations for the discrepancy of rates of depression in men and women. The first explanation is women are more likely than men to seek treatment [7]. Another theory is psychologists and psychiatrists are more likely to diagnose a woman as having depression than they would diagnose a man as suffering from depression as an extension of the stereotype women are the weaker sex [8].

Suicidal ideation is a term for thoughts about or an unusual preoccupation with suicide. The range of suicidal ideation varies greatly from fleeting to detailed planning and unsuccessful attempts, which may be deliberately constructed to fail or be discovered, or may be fully planned to result in death. Although most people who undergo suicidal ideation do not go on to make suicide attempts, a significant proportion do [9]. Suicidal ideation is generally associated with depression; however, it seems to have associations with many other psychiatric disorders, life events, and family events, all of which may increase the risk of suicidal ideation [10].

Depressive symptoms may also affect the process of socialization, family relationships and school performance [11]. Adolescents presenting depressive symptoms are also at increased risk for alcohol or substance abuse and antisocial behaviours [12]. Most young people with suicide ideation also show strong signs of depression [13]. Thus suicidal ideas and acts relate strongly to depression. However depression does not always lead to suicidal thoughts and behaviours. Around $40 \%$ of adolescents with diagnosed depression do not report suicide ideation [14]. Female adolescents have rates of depression that are approximately twice those of males and these gender differences appear to be reflected in the higher rates of suicidal ideation and attempts by females [15].

Somatic symptoms are defined as distressing physical or bodily symptoms that are medically unexplained, including pain. In somatic symptom disorder the responses to somatic symptoms is excessive and causes intense fear, concerns, and disturbances in optimal functioning. Somatic complaints without an apparent physical cause are common among children and adolescents. The most common complaints include headaches, stomach aches, musculoskeletal pains, back pain, dizziness, and fatigue [16-17]. Young boys and girls are equally likely to have somatic symptoms, but girls begin to report more somatic symptoms than boys in adolescence, and this difference continues into adulthood [18].

Children often present with multiple somatic complaints. It has been stated that $50 \%$ of children report more than one somatic complaint. About $15 \%$ report four or more and $1 \%$ have as many as 12 symptoms. This pattern is more common in adolescents than children and among girls than boys. Apart from somatisation disorder, children with multiple somatic symptoms show more symptoms of depression and anxiety than children with fewer or no somatic symptoms [19-20]. Many factors may contribute to the form and extent to which depression presents in the form of somatic symptoms. Female gender has been confirmed to be closely associated with somatization in many studies covering differential aspects on various theoretical levels [21].

In the Indian education system, board examination, which starts at the secondary level of education, is very important because this level provides the base for future education and students face excessive anxiety. Students have anxiety about their marks, performance and also for their academic achievement. The board exam is the fear in itself. On one hand they wish to secure good percentage of marks for getting admission for their future education and the other hand they also want to prove themselves better than others in this highly competitive age. Sometimes children are pressurized by their parent's expectations, so they suffer from pre-examination anxiety. Persistent level of examination anxiety (EA) causes a state of distress one experiences when being evaluated or when thinking about prospective evaluations, which typically lead to reduced performances. In fact, academic examinations have been considered as one of the most acute stresses experienced by students. 
The purpose of this study was to understand the suicide behaviour/ideation and somatic symptoms expressed by students appearing for their $10^{\text {th }}$ and $12^{\text {th }}$ grade board exams.

\section{METHODOLOGY}

\section{Research Hypothesis}

Hypothesis 1: Females will have significantly more somatic symptoms than males.

Hypothesis 2: Females will have significantly more suicidal ideations symptoms than males.

Hypothesis 3: Groups with higher depressive symptoms will have higher somatic symptoms than group with low depressive symptoms.

Hypothesis 4: Groups with higher depressive symptoms will have higher suicidal ideations than group with low depressive symptoms.

Hypothesis 5: There will be a significant interaction between gender and levels of depression

\section{Sampling strategy}

The survey method will be used to recruit participants using the snowball sampling technique. This can be considered a 2 (depression) $\times 2$ (gender of the adolescent) design as there are two independent variables. The first independent variable depressive symptoms, has to two levels, high and low, and gender will have two levels, males and females. The dependent measures will be the students rating on suicidal ideation and somatic symptoms.

\section{Participants}

The participants selected for the study were adolescents of age from 15 to 17, this criteria was also set as BDI can be used for adolescents of age only 15 and above. Also, the participants who were appearing for 10 th and 12th grade boards were targeted. This selection was made specifically made as there has been reported a significant rise in suicide attempts made by students appearing for board exams. The total sample size was 120, 30 participants in each group. The four groups categorised were females with high depressive symptoms, females with low depressive symptoms, males with high depressive symptoms, males with low depressive symptoms. Assent from the participants and informed consent from the parents were obtained.

\section{Procedure}

Data collection was done by purposive and snow ball sampling. The tests were administered in various settings home, tuitions, field, classroom and one-on-one basis. The participants were made to a consent form by their parents or guardians for participation in the study. The instructions given to the participants were that they have to go through each question and select or tick against answer that best applies to them in the last two weeks. The tests were administered in the following order (the tests were attached one behind the other) viz. Beck Depression Inventory (BDI), Patient Health Questionnaire -15 and The Suicide Behaviours Questionnaire - Revised (SBQ-R). This order was formulated so that screening of students with depressive symptoms and their scores on each of the following inventories could be calculated correspondingly. Data collection was completed within a period of 1 month.

\section{Instruments used in the study}

1. Beck Depression Inventory (BDI): This is a scale that evaluates depression in its emotional, cognitive and motivational components with 21 items and a total score of $0-63$. Scores in the range of 10-15 reflect mild depression while 16-23 reflect moderate depression and scores above 24 indicate severe depression [21-22].

2. Patient Health Questionnaire -15 (PHQ-15): The scale is a self-administered version of the PRIME-MD diagnostic instrument for common mental disorders. The PHQ-15 comprises 15 somatic symptoms from the PHQ, each symptom scored from 0 ("not bothered at all") to 2 ("bothered a lot") [23].

3. The Suicide Behaviours Questionnaire - Revised (SBQ-R): It is a psychological selfreport questionnaire designed to identify risk factors for suicide in children and adolescents 
between ages 13 and 18 . The four-question test is filled out by the child and takes approximately five minutes to complete. The questionnaire has been found to be reliable and valid in recent studies [24].

\section{STATISTICAL ANALYSIS}

A MANOVA was conducted since there are two dependent variables. The analysis is to compare suicidal ideation and somatic symptoms between males and females and also between high depressives and no depressives. It is also assumed that high depressive females will show the highest amount of somatic symptoms and suicidal ideation. All the assessments were done using the computerised software SPSS version 16.0

\section{RESULTS}

Table 1: Mean and SD for the different groups

\begin{tabular}{|c|c|c|c|c|}
\hline \multicolumn{5}{|c|}{ Descriptive Statistics } \\
\hline & Gender & $\begin{array}{c}\text { Depression } \\
\text { Levels }\end{array}$ & Mean & $\begin{array}{c}\text { Std. } \\
\text { Deviation }\end{array}$ \\
\hline \multirow{9}{*}{$\begin{array}{l}\text { Suicidal } \\
\text { Ideation }\end{array}$} & \multirow[t]{3}{*}{ Female } & Low & 4.1 & 1.494 \\
\hline & & High & 8.57 & 3.812 \\
\hline & & Total & 6.33 & 3.648 \\
\hline & \multirow[t]{3}{*}{ Male } & Low & 4.67 & 2.963 \\
\hline & & High & 8.07 & 3.423 \\
\hline & & Total & 6.37 & 3.608 \\
\hline & \multirow[t]{3}{*}{ Total } & Low & 4.38 & 2.344 \\
\hline & & High & 8.32 & 3.601 \\
\hline & & Total & 6.35 & 3.613 \\
\hline \multirow{9}{*}{$\begin{array}{l}\text { Somatic } \\
\text { Symptoms }\end{array}$} & \multirow[t]{3}{*}{ Female } & Low & 6.13 & 2.529 \\
\hline & & High & 12 & 4.136 \\
\hline & & Total & 9.07 & 4.506 \\
\hline & \multirow[t]{3}{*}{ Male } & Low & 4.6 & 4.399 \\
\hline & & High & 9.73 & 3.75 \\
\hline & & Total & 7.17 & 4.809 \\
\hline & \multirow[t]{3}{*}{ Total } & Low & 5.37 & 3.64 \\
\hline & & High & 10.87 & 4.077 \\
\hline & & Total & 8.12 & 4.737 \\
\hline
\end{tabular}

Although Box's test is significant, since the sample sizes are equal, the results can be discarded. Pillai's Trace test gives us significance for gender $(p=0.01)$ and depression level $(p=0.0001)$. Based on these $p-$ values it can be said that there is a significant difference between males and females, and between those with high depression and low depression for somatic symptoms and suicidal ideation. Levene's test is nonsignificant for somatic symptoms $(\mathrm{p}=0.183)$ but it is significant for suicidal ideation $(\mathrm{p}=0.001)$ indicating that the assumption of homogeneity of variance has not been met for suicidal ideation.

The multivariate table is especially useful because it takes into account the correlation between the dependent variables and so for these data has more power to detect group differences. The values of $p$ in Table 2 indicate that the depression level has a significant impact on both the dependent variables but the gender impacts only somatic symptoms. So hypotheses 3 and 4 are proved. There was no significant interaction between gender and depression levels. Based on the data from both tables it appears obvious 
that somatic symptoms and suicidal ideation are significantly higher in those with high depression. Somatic symptoms are significantly higher in females than in males proving hypothesis 1 . Finally women with high depression scores have more somatic symptoms and suicidal ideation than any other group.

Table 2: Multivariate test results for gender, depression levels and the interaction between the two for both the dependent variables.

\begin{tabular}{|c|c|c|c|c|c|c|c|}
\hline Source & $\begin{array}{c}\text { Dependent } \\
\text { Variable }\end{array}$ & $\begin{array}{l}\text { Type III } \\
\text { Sum of } \\
\text { Squares }\end{array}$ & $\mathrm{df}$ & $\begin{array}{l}\text { Mean } \\
\text { Square }\end{array}$ & $\mathrm{F}$ & Sig. & $\begin{array}{c}\text { Partial } \\
\text { Eta } \\
\text { Squared }\end{array}$ \\
\hline \multirow[t]{2}{*}{$\begin{array}{c}\text { Corrected } \\
\text { Model }\end{array}$} & $\begin{array}{l}\text { Suicidal } \\
\text { Ideation }\end{array}$ & $472.700^{\mathrm{a}}$ & 3 & 157.567 & 16.914 & 0.0001 & .304 \\
\hline & $\begin{array}{c}\text { Somatic } \\
\text { Symptoms }\end{array}$ & $1019.833^{b}$ & 3 & 339.944 & 23.891 & 0.0001 & .382 \\
\hline \multirow[t]{2}{*}{ Intercept } & $\begin{array}{l}\text { Suicidal } \\
\text { Ideation }\end{array}$ & 4838.700 & 1 & 4838.700 & 519.424 & 0.0001 & .817 \\
\hline & $\begin{array}{c}\text { Somatic } \\
\text { Symptoms }\end{array}$ & 7905.633 & 1 & 7905.633 & 555.610 & 0.0001 & .827 \\
\hline \multirow{2}{*}{$\begin{array}{c}\text { Gender * } \\
\text { Depression } \\
\text { Level }\end{array}$} & $\begin{array}{l}\text { Suicidal } \\
\text { Ideation }\end{array}$ & 8.533 & 1 & 8.533 & .916 & 0.341 & .008 \\
\hline & $\begin{array}{c}\text { Somatic } \\
\text { Symptoms }\end{array}$ & 4.033 & 1 & 4.033 & .283 & 0.595 & .002 \\
\hline \multirow[t]{2}{*}{ Gender } & $\begin{array}{l}\text { Suicidal } \\
\text { Ideation }\end{array}$ & .033 & 1 & .033 & .004 & 0.952 & .000 \\
\hline & $\begin{array}{c}\text { Somatic } \\
\text { Symptoms }\end{array}$ & 108.300 & 1 & 108.300 & 7.611 & 0.007 & .062 \\
\hline \multirow[t]{2}{*}{$\begin{array}{l}\text { Depression } \\
\text { Level }\end{array}$} & $\begin{array}{l}\text { Suicidal } \\
\text { Ideation }\end{array}$ & 464.133 & 1 & 464.133 & 49.824 & 0.0001 & .300 \\
\hline & $\begin{array}{c}\text { Somatic } \\
\text { Symptoms }\end{array}$ & 907.500 & 1 & 907.500 & 63.779 & 0.0001 & .355 \\
\hline \multirow[t]{2}{*}{ Error } & $\begin{array}{l}\text { Suicidal } \\
\text { Ideation }\end{array}$ & 1080.600 & 116 & 9.316 & & & \\
\hline & $\begin{array}{c}\text { Somatic } \\
\text { Symptoms }\end{array}$ & 1650.533 & 116 & 14.229 & & & \\
\hline \multirow[t]{2}{*}{ Total } & $\begin{array}{l}\text { Suicidal } \\
\text { Ideation }\end{array}$ & 6392.000 & 120 & & & & \\
\hline & $\begin{array}{c}\text { Somatic } \\
\text { Symptoms }\end{array}$ & 10576.000 & 120 & & & & \\
\hline \multirow[t]{2}{*}{$\begin{array}{c}\text { Corrected } \\
\text { Total }\end{array}$} & $\begin{array}{l}\text { Suicidal } \\
\text { Ideation }\end{array}$ & 1553.300 & 119 & & & & \\
\hline & $\begin{array}{c}\text { Somatic } \\
\text { Symptoms }\end{array}$ & 2670.367 & 119 & & & & \\
\hline
\end{tabular}

\section{DISCUSSION}

The present study attempted to find gender differences in reporting of suicidal ideations and somatic symptoms by adolescents. It also aimed to find the differences in reporting of suicidal ideation and somatic symptoms by depressed group as compared to the group which show low or no depressive symptoms.

The hypothesis that females will report higher suicidal ideations than males was rejected as the analysis showed no significant difference in reporting higher of suicidal ideation by females as compared to males. 
This could be explained by other researchers that have studied the strong influence of depression on college students and high school students, especially the development of their suicide behaviour. Researchers studied the relationship between depression and suicidality in a sample of college students and found that only depression scores predicted current and past suicidality among college student participants, and scores on locus of control, hopelessness, masculinity, and femininity did not make significant contribution to the prediction of suicidality. But women did significantly differ from men when it came to somatic symptoms. This adds credence to the general belief that women experience more aches and pains as compared to men [25-26].

The group with depressive symptoms showed significantly greater somatic symptoms than group with low depressive symptoms. This finding is in line with previous researches identifying several psychosocial factors that predict the development and maintenance of pain and somatic complaints in children and adolescents, including depressive symptoms and stressful life events. Higher levels of depressive symptoms are related to higher pain intensity and more pain-related disability in adults, children, and adolescents. Depression has also been shown to increase the risk for pain occurrence in population-based studies. There is some evidence that psychosocial factors such as depression and stress play a stronger role in the development of recurrent pains for girls, as has been demonstrated in adult women, but additional work is needed to understand the role of these factors in adolescents [27-28].

The hypothesis that group with depressive symptoms will report higher suicidal ideations than group with low or no depressive symptoms was accepted. This is again in line with findings from other studies [29]. There was no interaction found between the gender and the levels of depression in impacting the suicidal ideation or somatic symptoms. Although the mean scores did vary, it was independent of the interaction of these two variables. In other words, it is important for therapists and researchers to study to look at gender only when considering somatic symptoms. Thoughts about suicide are a function of depression level and not of gender. It reinforces the idea that individuals with depression are more likely to consider ending their lives and this is not specific to women [30].

The foremost limitation of this study can be cited as limited sample size. The use of self-report measures of suicidal behaviours, somatic symptoms and depressive symptoms may be seen as a limitation of the current study. Participants may have provided certain responses for a variety of reasons (e.g., to please the experimenter or exaggerate current problems or faking good). Suicidal ideation and somatic symptoms are difficult outcomes to study because they are necessarily self-reported. The use of a non-clinical sample and a brief, general measure of suicide risk and somatic symptoms may also be the limitations of this study.

\section{CONCLUSIONS}

The present study revealed that adolescents with depressive symptoms show both significantly higher rates of suicidal ideations and somatic symptoms. Female students were more likely to experience somatic symptoms. As the group of adolescents selected for the study were appearing for their board exams and show these results, it is all the more alarming as previous studies have shown rise in suicide attempts made by this age group.

\section{REFERENCES}

1. Enns MW, Cox BJ. Personality dimensions and depression: review and commentary. Can J Psychiatry 1997;42(3):274-84.

2. Heim C, Binder EB. Current research trends in early life stress and depression: Review of human studies on sensitive periods, gene-environment interactions, and epigenetics. Exp Neurol 2012;233(1):102-11.

3. Beck AT. Cognitive therapy of depression. Guilford press; 1979.

4. Beck AT, Alford BA. Depression: Causes and treatment. University of Pennsylvania Press; 2009.

5. SéAguin L, Potvin L, St-Denis M, Loiselle J. Socio-environmental factors and postnatal depressive symptomatology: a longitudinal study. Wom Health 1999;29(1):57-72.

6. Piccinelli M, Wilkinson G. Gender differences in depression. Br J Psychiatry 2000;177(6):486-92. 
7. Kuehner C. Gender differences in unipolar depression: an update of epidemiological findings and possible explanations. Acta Psychiatr Scand 2003;108(3):163-74.

8. Marcotte D, Alain M, Gosselin MJ. Gender differences in adolescent depression: Gender-typed characteristics or problem-solving skills deficits?. Sex Roles 1999;41(1-2):31-48.

9. Hovey JD, King CA. Acculturative stress, depression, and suicidal ideation among immigrant and secondgeneration Latino adolescents. J Am Acad Child Adolesc Psychiatry 1996;35(9):1183-92.

10. Beck AT, Steer RA, Beck JS, Newman CF. Hopelessness, depression, suicidal ideation, and clinical diagnosis of depression. Suicide Life-Threat Behav 1993;23(2):139-45.

11. Birtchnell J. Depression and family relationships. A study of young, married women on a London housing estate. Br J Psychiatry 1988;153(6):758-69.

12. Shrier LA, Harris SK, Sternberg M, Beardslee WR. Associations of depression, self-esteem, and substance use with sexual risk among adolescents. Prevent Med 2001;33(3):179-89.

13. Abela JR, Hankin BL. Handbook of depression in children and adolescents. Guilford Press; 2008.

14. Cicchetti D, Toth SL. The development of depression in children and adolescents. Amer Psychol 1998;53(2):221-32.

15. Klomek AB, Marrocco F, Kleinman M, Schonfeld IS, Gould MS. Bullying, depression, and suicidality in adolescents. J Am Acad Child Adolesc Psychiatry 2007;46(1):40-9.

16. Kroenke K. Physical symptom disorder: a simpler diagnostic category for somatization-spectrum conditions. J Psychosom Res 2006;60(4):335-9.

17. Rost KM, Akins RN, Brown FW, Smith GR. The comorbidity of DSM-III-R personality disorders in somatization disorder. Gen Hosp Psychiatry 1992;14(5):322-6.

18. Campo JV, Fritsch SL. Somatization in children and adolescents. J Am Acad Child Adolesc Psychiatry 1994;33(9):1223-35.

19. Fritz GK, Fritsch S, Hagino O. Somatoform disorders in children and adolescents: a review of the past 10 years. J Am Acad Child Adolesc Psychiatry 1997;36(10):1329-38.

20. Lieb R, Zimmermann P, Friis RH, Höfler M, Tholen S, Wittchen HU. The natural course of DSM-IV somatoform disorders and syndromes among adolescents and young adults: a prospective-longitudinal community study. Eur Psychiatry 2002;17(6):321-31.

21. Beck AT, Steer RA, Carbin MG. Psychometric properties of the Beck Depression Inventory: Twenty-five years of evaluation. Clin Psychol Rev 1988;8(1):77-100.

22. Beck AT, Steer RA, Brown GK. Manual for the beck depression inventory-II. San Antonio, TX: Psychological Corporation ; 1996.

23. Kroenke K, Spitzer RL, Williams JB. The PHQ-15: validity of a new measure for evaluating the severity of somatic symptoms. Psychosom Med 2002;64(2):258-66.

24. Osman A, Bagge CL, Gutierrez PM, Konick LC, Kopper BA, Barrios FX. The Suicidal Behaviors Questionnaire-Revised (SBQ-R): validation with clinical and nonclinical samples. Assessment 2001;8(4):44354.

25. D'Zurilla TJ, Chang EC, Nottingham EJ, Faccini L. Social problem-solving deficits and hopelessness, depression, and suicidal risk in college students and psychiatric inpatients. J Clin Psychol 1998;54(8):1091107.

26. Garlow SJ, Rosenberg J, Moore JD, Haas AP, Koestner B, Hendin H, Nemeroff CB. Depression, desperation, and suicidal ideation in college students: results from the American Foundation for Suicide Prevention College Screening Project at Emory University. Depress Anxiety 2008;25(6):482-8.

27. Robinson MJ, Edwards SE, Iyengar S, Bymaster F, Clark M, Katon W. Depression and pain. Front Biosci 2009;14(1):5031-51.

28. Korff MV, Simon G. The relationship between pain and depression. Br J Psychiatry 1996;168(30):101-8.

29. Fishbain DA, Cutler R, Rosomoff HL, Rosomoff RS. Chronic pain-associated depression: antecedent or consequence of chronic pain? A review. Clin J Pain 1997;13(2):116-37.

30. Blatt SJ. Experiences of depression: Theoretical, clinical, and research perspectives. American Psychological Association; 2004.

\footnotetext{
Acknowledgements - Nil

Source of Funding - Nil

Conflict of Interest - Nil
} 